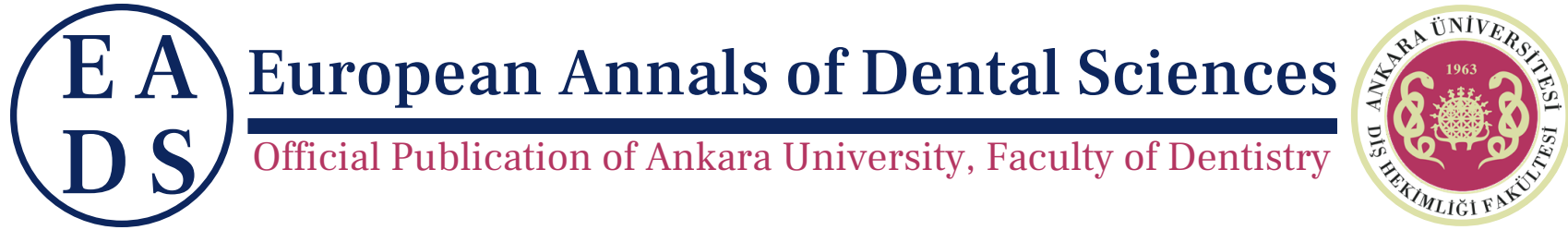

EADS, 2021, 48 (3), 88-94

\title{
Evaluation of Different Beverages' Effect on Microhardness and Surface Roughness of Different Artificial Teeth
}

\author{
Şule Tuğba Deniz ${ }^{1, *}$ and Pelin Özkan ${ }^{2}$ \\ ${ }^{1}$ Bezmialem Vakif University, Faculty of Dentistry, Department of Prosthodontics, Fatih, Istanbul, Turkey and \\ ${ }^{2}$ Ankara University, Faculty of Dentistry, Department of Prosthodontics, Besevler, Ankara, Turkey \\ *Corresponding Author; suletugba@yahoo.com
}

\begin{abstract}
Purpose: This study evaluated the microhardness and surface roughness of four artificial teeth type against various beverages. Materials \& Methods: Conventional acrylic resin, reinforced acrylic resin, microfiller composite resin, and nanofiller composite resin teeth were used. From each group, 10 maxillary first and second molars were immersed in 5 beverages (tea, filtered coffee, cola, cherry juice, and distilled water. The test period of 24 hours appears comparable to approximately 1 month of normal beverage consumption. The test periods used in this study were arranged according to this protocol and 1 week, 1 month, 3 months and 6 months of normal beverage consumptions were simulated. Vickers microhardness and surface roughness of denture teeth were measured for each test period.

Results: The microhardness values significantly decreased in all beverages especially in 6 th month. The surface roughness values significantly increased in all beverages especially in 3 th month. There were no statistically significant differences between the beverages. Microfiller composite resin denture teeth had the highest microhardness values and the lowest surface roughness values.

Conclusion: Different types of beverages consumed daily negatively affect the microhardness and surface roughness of artificial teeth. Microfiller composite resin teeth could have the ideal surface properties.
\end{abstract}

Key words: beverages; denture teeth; microhardness; nano-composite; surface roughness

\section{Introduction}

Rapid progress and new technologies in the dental materials industry offer dentists many different artificial tooth options. These developments allow the creation of a wide range from acrylic teeth to reinforced acrylic and composite resin teeth with different filler sizes. ${ }^{1,2}$ Nanotechnology is literally translated as 'the science of the little.. ${ }^{3}$ Nanotechnology in dentistry was first used in 1997 to improve the physical properties of restorative materials. ${ }^{4}$ The most recent development is the application of nanoparticle technology to composite resins. ${ }^{5}$ It has been possible to produce nano-sized filler particles and so a larger amount of filler could be added to the composite resin matrix. 6,7

Artificial teeth are important components of removable partial and complete dentures in terms of aesthetics, function and phonation. ${ }^{1,8,9}$ Preservation of occlusion, continuity of chewing activity and aesthetic requirements are the most sought features of artificial teeth. Materials used in artificial teeth production are expected to have good mechanical and physical properties such as color stability, smooth surface and wear resistance. ${ }^{10,11}$ Acrylic resin and porcelain are the most commonly used materials. However, none of them fully meet the characteristics required for an ideal artificial tooth. Porcelain teeth were preferred due to the rapid erosion of acrylic resin teeth. ${ }^{9}$ However, with the tendency of porcelain to break, acrylic teeth have gained popularity. Reinforced acrylic resin and new composite resin teeth have higher wear resistance and have replaced porcelain in the last years. ${ }^{1,7,10}$ Recently, composite materials have attracted attention as artificial teeth materials and have been introduced as modified, abrasion resistant dental materials. ${ }^{12}$ There is not enough information about the clinical performance of these new artificial teeth. Therefore, there is a need for studies evaluating the properties of artificial teeth. ${ }^{13}$ Composite resin artificial teeth available on the market differ in many properties. These features are filler shape, filler amount, polymer type and degree of crosslinking. ${ }^{1,14,15}$ With the effect of nanotechnology on dental materials, artificial teeth were also produced from 
Table 1. Artificial teeth used in the study

\begin{tabular}{|c|c|c|c|c|}
\hline Denture tooth & Manufacturer & Structure & Filler type & Matrix \\
\hline Major Dent & $\begin{array}{l}\text { Major Prodotti Dentari S.p.A., } \\
\text { Moncalieri, Italy }\end{array}$ & Conventional acrylic resin & - & Polymethyl methacrylate \\
\hline Integral & $\begin{array}{l}\text { Merz Dental GmbH, } \\
\text { Lütjenburg, Germany }\end{array}$ & Reinforced acrylic resin & - & $\begin{array}{l}\text { Cross-linked polymer network } \\
\text { (IPN) }\end{array}$ \\
\hline SR Orthosit PE & $\begin{array}{l}\text { Ivoclar Vivadent, Schaan, } \\
\text { Lichtenstein }\end{array}$ & Microfiller composite resin & Inorganic microfiller & Urethane dimethacrylate \\
\hline Veracia & Shofu Inc., Kyoto, Japan & Nanofiller composite resin & Nano composite filler & Urethane dimethacrylate \\
\hline
\end{tabular}

nano-filled composite. ${ }^{16}$ In these artificial teeth, nano-sized inorganic fillers are homogeneously distributed in the matrix without agglomeration. ${ }^{9}$ In this way, the smoothness of the surface was preserved even when the teeth were worn. As a result of the tests, it has been observed that nanocomposite artificial teeth are more durable and wear resistance than acrylic teeth and microfiller resin composite teeth. ${ }^{13,17,18}$

Hardness is one of the most studied mechanical properties for artificial tooth materials ${ }^{13}$ and is important in terms of protecting the formed occlusion and the continuity of the function. In addition to provide an aesthetic appearance, a smooth surface prevents the formation of a colored layer and plaque retention. ${ }^{4,19}$ Plaque accumulation occurs on rough surfaces following the attachment of microorganisms. For the oral usability of dental restorative materials, the average surface roughness should be below $0.2 \mu \mathrm{m} .{ }^{20}$

Chemical structure of the material, oral hygiene, denture cleaning habit, prosthesis usage time and nutrition habits effect the artificial teeth. Some beverages such as coffee, tea, red wine and even water can affect the mechanical and physical properties of composite materials. Chemicals in the formulations of beverages can cause erosion and surface degradation. ${ }^{21}$ These effects may vary depending on the amount and frequency of intake. ${ }^{22,23}$ The amount of liquid remaining in the mouth after swallowing is less than $1 \mathrm{ml}$. This limits the amount of beverage that comes into contact with teeth and restorations. ${ }^{2 / 4}$

In our study, it was aimed to compare surface hardness and surface roughness properties of four different artificial teeth when they exposed to frequently consumed beverages at different time periods. The null hypothesis was the chemical structure of artificial tooth doesn't affect the hardness and surface roughness.

\section{Materials and Methods}

The artificial teeth used in the study are shown in Table 1. They were grouped according to their chemical structures as conventional acrylic resin, reinforced acrylic resin, micro-filled composite resin and nano-filled composite resin teeth. Beverages used in the study are tea, filtered coffee, coke, cherry juice and distilled water as a control. 10 samples from each tooth group were randomly selected for each fluid medium. In total 200 upper 1st and 2nd molar artificial teeth were used for microhardness and surface roughness measurements from each tooth group. Each artificial tooth was embedded in $1 \mathrm{~cm}$ high and $1 \mathrm{~cm}$ diameter cylinder molds of acrylic resin with the buccal surfaces above and parallel to the floor. All specimens were kept in an oven (Köttermann $\mathrm{GmbH} \&$ Co.) in distilled water at $37^{\circ} \mathrm{C}$ for 24 hours before the test. Initial measurements were made before the specimens were immersed in solutions.

Beverages were prepared according to manufacturers' instructions (tea and filtered coffee). Solutions were prepared freshly every day during the test period. While the control group was kept in distilled water during the experiment, the other specimens were kept in four different solutions (tea, filtered coffee, cola, cherry juice). Each specimen was stored individually in $5 \mathrm{ml}$ plastic capped tubes. During the experiment, all specimens were kept in a dark environ-
Table 2. Immersion times in beverages and simulated time of denture usage equivalent to these times

\begin{tabular}{lc}
\hline $\begin{array}{l}\text { Test period (Immersion time in } \\
\text { beverages) }\end{array}$ & $\begin{array}{c}\text { Simulated time of denture } \\
\text { usage }\end{array}$ \\
\hline 336 minutes (5,6 hours) & 1 week \\
24 hours & 1 month \\
72 hours (3 days) & 3 months \\
144 hours ( 6 days) & 6 months \\
\hline
\end{tabular}

ment at $37^{\circ} \mathrm{C}$ to mimic the mouth environment.

We used the solutions without adding artificial saliva. In order to be able to carry out our in vitro study in accordance with in vivo conditions, we considered some criteria while determining the storage times in liquids; average daily drink consumption (average 3 glasses / 300ml), average drinking time of a drink (15 minutes for 1 glass / 200ml), the amount of beverage left in the mouth after the swallowing process (less than $1 \mathrm{ml}$ ), the amount of contact of drinks with tissue and restorations in the mouth before saliva reaches (20 seconds). We aimed to evaluate the changes in 6 months usage of prostheses, we determined a soaking period in a beverage that we can simulate this 6-month period, considering the material we use. Although there is no definite protocol on this subject in previous studies, Fraunhofer \& Rogers, ${ }^{25}$ in their study investigating the dissolution rate of enamel, accepted the 14-day soaking time as equivalent to the tooth-beverage contact that will occur as a result of 13 years of beverage intake. In the study of Güler et $\mathrm{al}^{26}$ for composite resin materials used in temporary restorations, it was stated that the 24 -hour beverage storage period simulated 1-month beverage intake. Considering the acrylic and composite resin materials used in our study, the immersion times of the samples in beverages and the simulated time processes are as shown in the Table 2. Measurements were made after each test period. Specimens taken from the solutions at the end of their immersiom time in beverages were washed under tap water and dried with a towel napkin before each measurement.

In the evaluation of surface roughness, a profilometer (Perthometer M2, Mahr GmbH, Göttingen, Germany) was used. The measurement length was set as $1.75 \mathrm{~mm}$, the cut-off value was taken as 0.25 and $n$ was taken as 5. Measurements were made from the flattest surface in the middle triple region of the buccal surfaces of the artificial tooth specimens. Three repeated measurements were recorded for each specimen and average roughness $(\mathrm{Ra})$ values were calculated. For microhardness values, a Vickers microhardness device (HVS 1000 Microhardness Tester Bulut Makine, Istanbul, Turkey) was used. $300 \mathrm{~g}$ load for 15 seconds was applied and three measurements were performed from each sample surfaceand the averages were calculated. The analysis of all data obtained from the measurements and the calculated values were made using IBM SPSS Statistics 19 statistical analysis program (SPSS for Windows, Version 19.0; IBM Corporation, New York). 
Table 3. Microhardness values $\left(\mathrm{kg} / \mathrm{mm}^{2}\right)$ and standart deviations of specimens stored in different beverages over time

\begin{tabular}{|c|c|c|c|c|c|c|}
\hline & Baseline & 1. Week & 1. Month & 3. Month & 6. Month & $\mathrm{p}$ \\
\hline Distilled water & $31.02 \pm 6.70 a$ & $26.69 \pm 3.72 b$ & $25.63 \pm 4.52 b c$ & $25.71 \pm 4.36 b c$ & $23.33 \pm 2.51 c$ & $0.000 *$ \\
\hline Tea & $30.76 \pm 5.91 a$ & $25.39 \pm 4.34 b$ & $25.79 \pm 4.63 b c$ & $25.34 \pm 5.64 b c$ & $22.64 \pm 3.35 c$ & $0.000 *$ \\
\hline Filtered Coffee & $28.48 \pm 4.37 a$ & $26.38 \pm 4.20 a$ & $25.81 \pm 5.31 a$ & $25.82 \pm 4.71 a$ & $22.65 \pm 3.53 b$ & $0.000 *$ \\
\hline Cola & $28.92 \pm 4.43 a$ & $26.17 \pm 4.02 \mathrm{ab}$ & $25.79 \pm 5.34 b$ & $24.75 \pm 5.36 b$ & $24.05 \pm 5.98 b$ & $0.000^{*}$ \\
\hline Cherry Juice & $29.64 \pm 3.95 a$ & $25.08 \pm 3.82 b$ & $25.08 \pm 4.87 \mathrm{~b}$ & $24.27 \pm 4.83 b$ & $23.92 \pm 5.13 b$ & $0.000 *$ \\
\hline
\end{tabular}

$* \mathrm{p}<0.01$ (Statistically different.)

For each analysis of variance, Tukey HSD results are indicated by the lettering method next to the mean \pm standard deviation results. For each line; same letters show that there is no difference between groups, and different letters show that the difference between groups is important.

Table 4. Microhardness values $\left(\mathrm{kg} / \mathrm{mm}^{2}\right)$ and standart deviations of different artificial teeth over time

\begin{tabular}{|c|c|c|c|c|c|c|}
\hline & Baseline & 1. Week & 1. Month & 3. Month & 6. Month & $\mathrm{p}$ \\
\hline Integral & $25.54 \pm 2.43 a$ & $23.22 \pm 1.51 b$ & $21.76 \pm 1.00 \mathrm{c}$ & $21.18 \pm 1.62 c$ & $20.18 \pm 1.71 d$ & $0.000 *$ \\
\hline Major & $25.55 \pm 1.95 a$ & $22.37 \pm 1.76 b$ & $22.31 \pm 1.20 \mathrm{~b}$ & $21.97 \pm 1.36 \mathrm{~b}$ & $20.19 \pm 2.00 \mathrm{C}$ & $0.000 *$ \\
\hline Veracia & $32.56 \pm 3.80 a$ & $26.45 \pm 1.69 b$ & $24.93 \pm 1.43 c$ & $24.64 \pm 1.40 \mathrm{C}$ & $23.96 \pm 1.79 c$ & $0.000 *$ \\
\hline Orthosit & $35.41 \pm 3.14 a$ & $31.73 \pm 1.66 b$ & $33.49 \pm 1.77 c$ & $32.93 \pm 2.45 b c$ & $28.93 \pm 3.47 d$ & $0.000 *$ \\
\hline
\end{tabular}

$* \mathrm{p}<0.01$ (Statistically different.)

For each analysis of variance, Tukey HSD results are indicated by the lettering method next to the mean \pm standard deviation results. For each line; same letters show that there is no difference between groups, and different letters show that the difference between groups is important.

Table 5. Microhardness values $\left(\mathrm{kg} / \mathrm{mm}^{2}\right)$ and standart deviations of different artificial teeth according to beverages

\begin{tabular}{|c|c|c|c|c|c|c|}
\hline & Distilled Water & Tea & Filtered Coffee & Cola & Cherry Juice & $\mathrm{p}$ \\
\hline Integral & $23.01 \pm 1.33$ & $22.22 \pm 2.72$ & $22.59 \pm 2.26$ & $22.04 \pm 2.42$ & $22.01 \pm 3.40$ & 0.225 \\
\hline Major & $23.01 \pm 2.39$ & $22.13 \pm 2.27$ & $22.25 \pm 2.43$ & $21.98 \pm 2.58$ & $23.00 \pm 2.24$ & 0.074 \\
\hline Veracia & $27.97 \pm 5.34 a$ & $26.95 \pm 4.01 a$ & $26.38 \pm 2.83 a b$ & $26.37 \pm 2.90 \mathrm{ab}$ & $24.87 \pm 2.90 b$ & $0.002 *$ \\
\hline Orthosit & $31.91 \pm 4.05$ & $32.64 \pm 4.24$ & $32.08 \pm 3.25$ & $33.35 \pm 2.26$ & $32.50 \pm 2.43$ & 0.226 \\
\hline
\end{tabular}

$* \mathrm{p}<0.01$ (Statistically different.)

For each analysis of variance, Tukey HSD results are indicated by the lettering method next to the mean \pm standard deviation results. For each line; same letters show that there is no difference between groups, and different letters show that the difference between groups is important.

\section{Results}

For microhardness and surface roughness measurement results, one-way analysis of variance (ANOVA) was used to determine the differences between artificial teeth and beverages. The nonparametric Friedman Test was used to determine the differences between repeated measurements. When the difference between the groups was found to be significant in one-way analysis of variance and Friedman Test, a comparison was made with Tukey HSD, one of the multiple comparison tests, in pairs. According to the initial values, all groups created with artificial tooth specimens are homogeneous. Beverage and time, artificial tooth and time, artificial tooth and beverage interactions were evaluated for each test method.

There was a significant decrease from the baseline to the 6th month in all beverages for the microhardness values of all artificial tooth groups (Tukey HSD test, $\mathrm{p}<0.01$ ). However, at the end of the 6th month, no significant difference was observed between the beverages in terms of microhardness in the overall specimens (Friedman test, $\mathrm{p}>0.01$ ) (Table 3). When the baseline microhardness values of different artificial teeth were compared, Veracia (32.55 $\left.\mathrm{kg} / \mathrm{mm}^{2}\right)$ and Orthosit $\left(35.41 \mathrm{~kg} / \mathrm{mm}^{2}\right)$ teeth were significantly higher than Integral $\left(25.76 \mathrm{~kg} / \mathrm{mm}^{2}\right)$ and Major $\left(25.54 \mathrm{~kg} / \mathrm{mm}^{2}\right)$ teeth (Tukey HSD test, $\mathrm{p}<0.01$ ) (Table 4). The highest microhardness values for each artificial tooth group were for the specimens waiting in distilled water (control group) while the difference wasn't statistically significant (Tukey HSD test, $\mathrm{p}>0.01$ ). However, Veracia teeth waiting in distilled water had higher microhardness values compared to other beverage (Table 5).

It has been stated that the amount of surface roughness of dental materials should be less than $0.2 \mu \mathrm{m}$. Considering this situation, the average surface roughness values revealed in our study increased above $0.2 \mu \mathrm{m}$ from the 1st month in all beverages for all artificial tooth groups. While the surface roughness values increased over time during the test period, the most significant increase was observed in the 3 rd and 6th month measurements (Tukey HSD test, $\mathrm{p}<0.01)$. Although the highest roughness values were found in the specimens stored in cola and cherry juice in the 3rd month and 6th month measurements, this difference was not significant (Friedman test, $\mathrm{p}>0.01$ ) (Table 6).

When the initial surface roughness values of different artificial tooth specimens are compared, Orthosit $(0.16 \mu \mathrm{m})$ teeth have lower values than Integral $(0.19 \mu \mathrm{m})$, Major $(0.18 \mu \mathrm{m})$ and Veracia $(0.18$ $\mu \mathrm{m})$ teeth, but this difference is statistically was not significant (Tukey HSD test, p> 0.05). At the end of the 6th month, the lowest surface roughness values belonged to Orthosit teeth (Tukey HSD test, $\mathrm{p}<0.01$ ) (Table 7). Specimens in distilled water had the lowest roughness values at all times, but this result was also not significant (Tukey HSD test, $\mathrm{p}>0.05$ ) (Table 8).

\section{Discussion}

In our study, which we planned considering that it will assist the dentist's choice of artificial teeth, we chose four different types of artificial tooth materials to see how the chemical composition of artificial teeth affects the mechanical and physical properties. The null hypothesis as 'Chemical structure of artificial tooth doesn't affect the hardness and surface roughness.' is rejected.

The most important feature of nanocomposite artificial teeth is that they have a homogeneous structure because this material is not very cross-linked but contains nano-sized inorganic fillers that are evenly distributed without agglomeration in the matrix resin. These properties can provide smooth surfaces against wear 
Table 6. Surface roughness values $(\mu \mathrm{m})$ and standart deviations of specimens stored in different beverages over time

\begin{tabular}{|c|c|c|c|c|c|c|}
\hline & Baseline & 1. Week & 1. Month & 3. Month & 6. Month & $\mathrm{p}$ \\
\hline Distilled water & $0.19 \pm 0.07 a$ & $0.20 \pm 0.05 a b$ & $0.20 \pm 0.05 a$ & $0.23 \pm 0.06 b c$ & $0.26 \pm 0.07 \mathrm{c}$ & $0.000^{*}$ \\
\hline Tea & $0.18 \pm 0.05 a$ & $0.21 \pm 0.06 \mathrm{ab}$ & $0.21 \pm 0.06 \mathrm{ab}$ & $0.24 \pm 0.07 b c$ & $0.26 \pm 0.07 \mathrm{c}$ & $0.000 *$ \\
\hline Filtered Coffee & $0.19 \pm 0.05 a$ & $0.20 \pm 0.04 a$ & $0.20 \pm 0.04 a$ & $0.25 \pm 0.05 b$ & $0.26 \pm 0.05 b$ & $0.000^{*}$ \\
\hline Cola & $0.19 \pm 0.04 a$ & $0.20 \pm 0.05 a$ & $0.21 \pm 0.05 a$ & $0.26 \pm 0.06 b$ & $0.26 \pm 0.06 b$ & $0.000^{*}$ \\
\hline Cherry Juice & $0.19 \pm 0.06 a$ & $0.21 \pm 0.06 a$ & $0.21 \pm 0.06 a$ & $0.25 \pm 0.07 b$ & $0.28 \pm 0.08 b$ & $0.000 *$ \\
\hline
\end{tabular}

$* \mathrm{p}<0.01$ (Statistically different.)

For each analysis of variance, Tukey HSD results are indicated by the lettering method next to the mean \pm standard deviation results. For each line; same letters show that there is no difference between groups, and different letters show that the difference between groups is important.

Table 7. . Surface roughness values $(\mu \mathrm{m})$ and standart deviations of different artificial teeth over time

\begin{tabular}{|c|c|c|c|c|c|c|}
\hline & Baseline & 1. Week & 1. Month & 3. Month & 6. Month & $\mathrm{p}$ \\
\hline Integral & $0.19 \pm 0.05 a$ & $0.21 \pm 0.04 a b$ & $0.22 \pm 0.04 b$ & $0.26 \pm 0.06 c$ & $0.28 \pm 0.06 c$ & $0.000 *$ \\
\hline Major & $0.19 \pm 0.07 a$ & $0.20 \pm 0.06 a$ & $0.20 \pm 0.06 a$ & $0.25 \pm 0.07 b$ & $0.25 \pm 0.08 b$ & $0.000 *$ \\
\hline Veracia & $0.19 \pm 0.06 a$ & $0.20 \pm 0.05 a$ & $0.20 \pm 0.06 a$ & $0.24 \pm 0.06 b$ & $0.28 \pm 0.07 \mathrm{c}$ & $0.000 *$ \\
\hline Orthosit & $0.17 \pm 0.05 a$ & $0.20 \pm 0.05 a$ & $0.20 \pm 0.05 a$ & $0.24 \pm 0.06 b$ & $0.25 \pm 0.06 b$ & $0.000^{*}$ \\
\hline
\end{tabular}

$* \mathrm{p}<0.01$ (Statistically different.)

For each analysis of variance, Tukey HSD results are indicated by the lettering method next to the mean \pm standard deviation results. For each line; same letters show that there is no difference between groups, and different letters show that the difference between groups is important.

Table 8. Surface roughness values of $(\mu \mathrm{m})$ and standart deviations of different artificial teeth according to beverages

\begin{tabular}{|c|c|c|c|c|c|c|}
\hline & Distilled Water & Tea & Filtered Coffee & Cola & Cherry Juice & $\mathrm{p}$ \\
\hline Integral & $0.22 \pm 0.06$ & $0.24 \pm 0,08$ & $0.23 \pm 0,05$ & $0.22 \pm 0,05$ & $0.25 \pm 0,06$ & 0,138 \\
\hline Major & $0.22 \pm 0.08 a$ & $0.20 \pm 0,07 a$ & $0.25 \pm 0,07 b$ & $0.21 \pm 0,05 a$ & $0.22 \pm 0,09 a$ & $0,015^{* *}$ \\
\hline Veracia & $0.22 \pm 0.07 a b$ & $0.21 \pm 0,05 \mathrm{c}$ & $0.20 \pm 0,05 b$ & $0.24 \pm 0,08 a$ & $0.23 \pm 0,08 \mathrm{ab}$ & $0,034 * *$ \\
\hline Orthosit & $0.20 \pm 0.05 a$ & $0.23 \pm 0,07 b$ & $0.20 \pm 0,05 a$ & $0.23 \pm 0,06 a$ & $0.21 \pm 0,06 a$ & $0,008 *$ \\
\hline
\end{tabular}

$* \mathrm{p}<0.01 * * \mathrm{p}<0.05$ (Statistically different.)

For each analysis of variance, Tukey HSD results are indicated by the lettering method next to the mean \pm standard deviation results. For each line; same letters show that there is no difference between groups, and different letters show that the difference between groups is important.

in nanocomposite teeth. However, it can be thought that it will have a limited abrasion resistance due to its polymethylmethacrylate content. ${ }^{1,18}$ Studies have shown that this material has wear and microhardness properties similar to micro-filled and cross-linked acrylic resin teeth. ${ }^{18,27}$ The initial microhardness values of the artificial teeth were $36.18 \mathrm{~kg} / \mathrm{mm}^{2}$ for Orthosit, $32.55 \mathrm{~kg} / \mathrm{mm}^{2}$ for Veracia, $25.76 \mathrm{~kg} / \mathrm{mm}^{2}$ for Integral, $25.54 \mathrm{~kg} / \mathrm{mm}^{2}$ for Major. The differences in the microhardness values of the specimens that have not been processed yet are due to the differences in the chemical structure. It is seen that the material used for Veracia and Orthosit teeth is composite, giving them an initial advantage compared to other teeth with an acrylic structure. When the initial surface roughness values of different artificial tooth specimens were compared, Orthosit $(0.16 \mu \mathrm{m})$ teeth had lower values than Integral (0.19 $\mu \mathrm{m})$, Major $(0.18 \mu \mathrm{m})$ and Veracia $(0.18 \mu \mathrm{m})$ teeth.

Hardness appears to be associated with wear resistance and harder materials are expected to wear less. ${ }^{13}$ There are various opinions about the correlation between the hardness and wear resistance of composite resin-based restorative materials. A group of researchers stated that it is difficult to obtain healthy results by only measuring surface hardness in determining wear resistance and emphasized that surface hardness value is only one of the important parameters in determining the amount of wear. ${ }^{28}$

The different behavior of composite materials depends on the differences in composition and filler distribution of the matrix. Factors affecting the properties of composites are monomers, fillers and binding agents. ${ }^{1,29}$ Filler content is also related to color stability, hardness and compression strength. Increased filler ratio reduces water absorption, which results in less degradation on the surface. ${ }^{1,30,31}$ However, changes may occur as a result of the continuous and natural decomposition of the material surface in the liquid medium. ${ }^{32}$ Filler and matrix connection breaks with water absorption. This linkage can also be weakened by chemical solvents. The increase in the surface roughness of the Veracia teeth in the 6th month may have occurred as a result of the weakening of the bond between the filler and the matrix.

The main differences between restorative composite resins and composite resins used for artificial teeth are the filler amount and size. The amount of filler is higher in restorative composite resins. In this way, the coefficients of thermal expansion become similar to the natural tooth structure and polymerization shrinkage is also reduced. However, composite resin artificial teeth consist of at least two layers, and after the enamel layer comes a layer without fillers. This multi-layer structure enhances the aesthetic appearance. If the filler amounts of these two layers are very different, the thermal stress between them increases and this prevents them from being tightly bonded to each other. Also, there is no problem of polymerization shrinkage for composite resin teeth. ${ }^{13}$

Acrylic resin teeth contain a negligible amount of filler. There is a positive linear relationship between hardness and filler amount. ${ }^{13}$ Larger fillers provide greater stiffness and bending strength. However, smaller fillers also allow smoother surfaces to be obtained. Loyaga-Rendon et al13 attributed the different hardness values of two different composite resin teeth containing the same amount of filler to the filler sizes. The macro-filled composite resin tooth gave greater microhardness values than the micro-filled one. In our study, Orthosit teeth, which are composite resin teeth with micro-fillers, had higher microhardness values than Veracia teeth, which are composite resin teeth with nano-fillers. Orthosit and Veracia composite resin teeth we used in our study contain $42.9 \%$ and $5.9 \%$ inorganic filler content, respectively. ${ }^{13}$ In the study by Loyaga-Rendon et al ${ }^{13}$ investigating the structural properties of artificial teeth, it was observed that the filling distribution of Orthosit teeth was more homogeneous. Less filler amount of Veracia 
teeth may cause an increase in roughness values.

In general, the enamel layer of artificial teeth should have properties such as cracking, deterioration in solvents and resistance to abrasion. In our study, we did not apply any abrasion and polishing process to artificial teeth. We have used as flat surfaces as possible by measuring from the buccal middle triple regions of the specimens. Kawano et $\mathrm{al}^{11}$ did not perform any abrasion and polishing process while measuring the microhardness of artificial teeth. We ensured that the enamel layers preserve their properties without abrasion of the artificial tooth specimens we use.

The effect of beverages can be strong depending on the structural properties of artificial teeth such as chemical composition or external properties such as finishing and polishing. ${ }^{27}$ Moreover, the effect of drinks on the characteristics of artificial teeth may be directly related to the frequency and amount of intake. ${ }^{22}$ Previous studies ${ }^{23,33}$ demonstrated that storage in water, the $\mathrm{pH}$ of the stored medium and the ionic composition of organic acids, foods and beverages affect the mechanical properties of dental materials. However, it has been observed that the temperature and $\mathrm{pH}$ values of the beverages are mostly effective in studies evaluating the erosive effects on enamel. ${ }^{34}$ In our study, in parallel with the researches, liquid environments containing artificial tooth specimens were kept in the oven at $37^{\circ} \mathrm{C}$. Sarl et al ${ }^{35}$ concluded that foods and beverages with low $\mathrm{pH}$ cause lower microhardness value and more surface roughness on enamel and composite samples. Aliping-Mckenzie et $\mathrm{al}^{36}$ suggested that the surface hardness of glass ionomer and compomer samples is affected not only by low $\mathrm{pH}$ values but also by the chemical composition of acidic beverages. Badra et $\mathrm{al}^{22}$ attributed the increase in surface roughness of composite resins with different fillers kept in coffee at $60^{\circ} \mathrm{C}$ to the high temperature of the solution. In our study, there was a significant decrease from the beginning to the 6th month in all beverages for the microhardness values of all artificial tooth groups. However, at the end of the 6th month, there was no significant difference between the solutions in terms of microhardness in general. There was no significant difference between beverages for all the time of measurement of surface roughness. The fact that cola and cherry juice has a lower $\mathrm{pH}$ compared to other beverages increases the surface roughness, while it is not thought to have a significant effect on microhardness.

Microhardness and roughness varied depending on the storage time of the specimens in beverages. Therefore, it is important to determine test times and measurement times in a way that reflects denture use. It is thought that the 6-day test period we determined can reflect the clinical conditions by simulating 6 -month denture use. $^{22,25,26}$ Teeth and denture surfaces come into contact with food or drink taken for a very short time before being washed by saliva. In studies where specimens were kept in solutions for a long time, this role of saliva was not taken into account. ${ }^{31,36}$ Therefore, while planning our study, we determined our test period by considering the possible contact time of intraoral tissues and restorations before being washed by saliva. The effects of saliva such as the buffering capacity, formation of a pellet layer and contribution to remineralization are difficult to imitate in vitro. These properties are more important for studies on enamel.

In studies, the differences in the surface hardness of artificial teeth have been attributed to the presence of cross-links for acrylic resin teeth, and to the difference in filling particles and composition for composite resin teeth. ${ }^{11,13,37-39}$ In the Vickers hardness measurement technique, it is possible to calculate the average and obtain information about the hardness of the entire structure, since the tip coincides with inorganic and organic structure. In composite resins, one of the heterogeneous measuring materials, the tip can correspond to the soft or hard area. For this reason, 3 measurements were made from each surface in our study.

Although hardness is a surface property, it is affected by water absorption decrease in the amount of filler leads to increased water absorption. ${ }^{30}$ In order for the surface hardness of the composite resin to decrease, the liquid in the environment must penetrate the resin matrix and cause filler release by weakening the filler silane bond. Studies ${ }^{11,13,18,28,38}$ have shown that microfilled composite resin artificial teeth have higher microhardness values. These studies support the result of our research. The addition of inorganic filler particles to the highly cross-linked polymer structures of microfilled composite resin teeth provided them higher hardness values.

Surface roughness is the 2-dimensional parameter of the material surface. As the surface free energy decreases on rough surfaces, the accumulation of food residues becomes easier. This results in an accumulation of stains, plaque and calculus. ${ }^{9,40}$ The softening of the resin matrix causes the filler particles to separate from the surface, resulting in a rough surface. ${ }^{22}$ Suzuki ${ }^{18}$ compared the surface roughness properties of four different artificial teeth (nano-composite, micro-filled composite, cross-linked acrylic resin, conventional acrylic resin). According to the results, the surface roughness of all artificial teeth showed lower values than conventional acrylic teeth. There was no significant difference between the roughness values of the nanocomposite artificial teeth and the micro-filled teeth and cross-linked acrylic teeth. These results are in line with our study. Bollen et $\mathrm{al}^{20}$ argued that the amount of surface roughness of the oral hard tissues should be less than $0.2 \mu \mathrm{m}$ in order to prevent the accumulation of plaque and thus to provide biocompatible restorations. Considering this situation, the average surface roughness values revealed in our study increased above $0.2 \mu \mathrm{m}$ from the 1st month in all solutions for all artificial tooth groups. While the surface roughness values increased with time during the test period, the most significant increase was observed in the 3rd and 6th month measurements.

\section{Conclusion}

The daily consumption of regular beverages can alter the surface characteristics and the microhardness of artificial teeth. To improve these mechanical and physical properties, new artificial teeth have been developed by controlling the filler particles and the polymer matrix. Based on the results of this study, microfiller composite resin teeth were recommended for their best mechanical properties.

\section{Acknowledgements}

This study was presented as an oral presentation in the FDI 2013 Istanbul 101st Annual World Dental Congress 28-31 August 2013. This study was supported by Ankara University Faculty of Dentistry Research Support Fund with project number 225.

\section{Author Contributions}

P.O. and S.T.D. planned the study design. S.T.D. prepared the samples and performed the laboratuary tests. P.O. evaluated the results. S.T.D. wrote the text and P.O. made the necessary corrections.

\section{Conflict of Interest}

The authors declare that there is no conflicts of interest.

\section{Authors' ORCID(s)}

S.T.D. $\quad 0000-0003-1373-6925$

P.O. $\quad 0000-0002-1146-4279$ 


\section{References}

1. Hao Z, Yin H, Wang L, Meng Y. Wear behavior of seven artificial resin teeth assessed with three-dimensional measurements. J Prosthet Dent. 2014;112(6):1507-12. doi:10.1016/j.prosdent.2014.04.030.

2. Mutlu-Sagesen L, Ergun G, Ozkan Y, Bek B. Color stability of different denture teeth materials: an in vitro study. J Oral Sci. 2001;43(3):193-205. doi:10.2334/josnusd.43.193.

3. Duke ES. Has dentistry moved into the nanotechnology era? Compend Contin Educ Dent. 2003;24(5):380-2.

4. Atabek D, Sillelioglu H, Olmez A. The efficiency of a new polishing material: nanotechnology liquid polish. Oper Dent. 2010;35(3):362-9. doi:10.2341/09-196-T.

5. Bayne SC. Dental biomaterials: where are we and where are we going? J Dent Educ. 2005;69(5):571-85.

6. Jung $M$, Sehr K, Klimek J. Surface texture of four nanofilled and one hybrid composite after finishing. Oper Dent. 2007;32(1):4552. doi:10.2341/06-9.

7. Uehara PN, Iegami CM, Tamaki R, Ballester RY, de Souza RM, Lagana DC. Analysis of behavior of the wear coefficient in different layers of acrylic resin teeth. J Prosthet Dent. 2019;121(6):967 e1-967 e6. doi:10.1016/j.prosdent.2019.02.022.

8. Koksal T, Dikbas I. Color stability of different denture teeth materials against various staining agents. Dent Mater J. 2008;27(1):139-144. doi:DOI 10.4012/dmj.27.139.

9. Yuzugullu B, Acar O, Cetinsahin C, Celik C. Effect of different denture cleansers on surface roughness and microhardness of artificial denture teeth. J Adv Prosthodont. 2016;8(5):333-338. doi:10.4047/jap.2016.8.5.333.

10. Kamonwanon P, Yodmongkol S, Chantarachindawong $R$, Thaweeboon S, Thaweeboon B, Srikhirin T. Wear resistance of a modified polymethyl methacrylate artificial tooth compared to five commercially available artificial tooth materials. J Prosthet Dent. 2015;114(2):286-92. doi:10.1016/j.prosdent.2015.01.013.

11. Kawano F, Ohguri T, Ichikawa T, Mizuno I, Hasegawa A. Shock absorbability and hardness of commercially available denture teeth. Int J Prosthodont. 2002;15(3):243-7.

12. Craig R, Powers J. Restorative dental materials, 11th edn, St. Louis: Mosby. 2002:348-370.

13. Loyaga-Rendon PG, Takahashi H, Hayakawa I, Iwasaki N. Compositional characteristics and hardness of acrylic and composite resin artificial teeth. J Prosthet Dent. 2007;98(2):141-9. doi:10.1016/S0022-3913(07)60047-X.

14. Imamura S, Takahashi H, Hayakawa I, Loyaga-Rendon PG, Minakuchi S. Effect of filler type and polishing on the discoloration of composite resin artificial teeth. Dent Mater J. 2008;27(6):802-8. doi:10.4012/dmj.27.802.

15. Jin S, Choi JW, Jeong CM, Huh JB, Lee SH, Lee $\mathrm{H}$, et al. Evaluating the Wear of Resin Teeth by Different Opposing Restorative Materials. Materials (Basel). 2019;12(22). doi:10.3390/ma12223684.

16. Mosharraf R, Ziaei F, Abbasi M. Effect of Denture Tooth Material on Load Transmission Under Denture Bases. J Dent (Tehran). 2018;15(5):325-331.

17. Ghazal M, Albashaireh ZS, Kern M. Wear resistance of nanofilled composite resin and feldspathic ceramic artificial teeth. J Prosthet Dent. 2008;100(6):441-8. doi:10.1016/S00223913(08)60262-0.

18. Suzuki S. In vitro wear of nano-composite denture teeth. J Prosthodont. 2004;13(4):238-43. doi:10.1111/j.1532849X.2004.04043.x.

19. Kakaboura A, Fragouli M, Rahiotis C, Silikas N. Evaluation of surface characteristics of dental composites using profilometry, scanning electron, atomic force microscopy and gloss-meter. J Mater Sci Mater Med. 2007;18(1):155-163. doi:10.1007/s10856006-0675-8.

20. Bollen CML, Lambrechts P, Quirynen M. Comparison of sur- face roughness of oral hard materials to the threshold surface roughness for bacterial plaque retention: A review of the literature. Dent Mater. 1997;13(4):258-269. doi:Doi 10.1016/S01095641(97)80038-3.

21. Tahmassebi JF, Duggal MS, Malik-Kotru G, Curzon MEJ. Soft drinks and dental health: A review of the current literature. J Dent. 2006;34(1):2-11. doi:DOI 10.1016/j.jdent.2004.11.006.

22. Badra VV, Faraoni J, Ramos RP, Palma-Dibb RG. Influence of different beverages on the microhardness and surface roughness of resin composites. Oper Dent. 2005;30(2):213-219.

23. West NX, Hughes JA, Addy M. Erosion of dentine and enamel in vitro by dietary acids: the effect of temperature, acid character, concentration and exposure time. J Oral Rehabil. 2000;27(10):875-880. doi:DOI 10.1046/j.13652842.2000.00583.x.

24. Jensdottir I, Holbrook P, Nauntofte B, Buchwald C, Bardow A. Immediate erosive potential of cola drinks and orange juices. J Dent Res. 2006;85(3):226-230. doi:Doi 10.1177/154405910608500304.

25. von Fraunhofer JA, Rogers MM. Dissolution of dental enamel in soft drinks. Gen Dent. 2004;52(4):308-12.

26. Guler AU, Yilmaz F, Kulunk T, Guler E, Kurt S. Effects of different drinks on stainability of resin composite provisional restorative materials. J Prosthet Dent. 2005;94(2):118-24. doi:10.1016/j.prosdent.2005.05.004.

27. Stober T, Lutz T, Gilde H, Rammelsberg P. Wear of resin denture teeth by two-body contact. Dent Mater. 2006;22(3):243-249. doi:10.1016/j.dental.2005.03.009.

28. Campanha NH, Pavarina AC, Jorge JH, Vergani CE, Machado AL, Giampaolo ET. The effect of long-term disinfection procedures on hardness property of resin denture teeth. Gerodontology. 2012;29(2):E571-E576. doi:10.1111/j.1741-2358.2011.00520.x.

29. Guler AU, Duran I, Yucel AC, Ozkan P. Effects of air-polishing powders on color stability of composite resins. J Appl Oral Sci. 2011;19(5):505-510.

30. Kim KH, Ong JL, Okuno O. The effect of filler loading and morphology on the mechanical properties of contemporary composites. J Prosthet Dent. 2002;87(6):642-649. doi:10.1067/mpr.2002.125179.

31. Yanikoglu N, Duymus ZY, Yilmaz B. Effects of different solutions on the surface hardness of composite resin materials. Dent Mater J. 2009;28(3):344-351. doi:DOI 10.4012/dmj.28.344.

32. Milleding P, Ahlgren F, Wennerberg A, Ortengren U, Karlsson S. Microhardness and surface topography of a composite resin cement after water storage. Int J Prosthodont. 1998;11(1):21-26.

33. Wongkhantee S, Patanapiradej V, Maneenut C, Tantbirojn D. Effect of acidic food and drinks on surface hardness of enamel, dentine, and tooth-coloured filling materials. J Dent. 2006;34(3):214-220. doi:10.1016/j.jdent.2005.06.003.

34. de Mesquita-Guimaraes KSF, Scatena C, Borsatto MC, Rodrigues AL, Serra MC. Effect of foods and drinks on primary tooth enamel after erosive challenge with hydrochloric acid. Braz Oral Res. 2015;29(1). doi:10.1590/1807-3107BOR2015.vol29.0096.

35. Sari ME, Koyuturk AE, Cankaya S. Günlük tüketilen yiyecek ve içeceklerin mine ve dolgu materyallerinin yüzey sertliği ve pürüzlülügüne etkisi. Atatürk Üniv Diş Hek Fak Derg. 2010;20(3):153-161.

36. Aliping-McKenzie M, Linden RWA, Nicholson JW. The effect of Coca-Cola and fruit juices on the surface hardness of glassionomers and 'compomers'. J Oral Rehabil. 2004;31(11):10461052. doi:DOI 10.1111/j.1365-2842.2004.01348.x.

37. Campanha NH, Pavarina AC, Vergani CE, Machado AL. Effect of microwave sterilization and water storage on the Vickers hardness of acrylic resin denture teeth. J Prosthet Dent. 2005;93(5):483-487. doi:10.1016/j.prosdent.2005.02.016.

38. Ersu B, Hannak W, Freesmeyer W. Tam ve bölümlü protezlerde kullanılan akrilik rezin dişlerin sertliklerinin karşılaştırılması. 
HÜ Diş Fak Derg. 2007;31:58-64.

39. Pavarina AC, Vergani CE, Machado AL, Giampaolo ET, Teraoka MT. The effect of disinfectant solutions on the hardness of acrylic resin denture teeth. J Oral Rehabil. 2003;30(7):749-752. doi:DOI 10.1046/j.1365-2842.2003.01145.x.
40. Hahnel S, Rosentritt M, Burgers R, Handel G. Adhesion of Streptococcus Mutans Nctc 10449 to Artificial Teeth: An in Vitro Study. J Prosthet Dent. 2008;100(4):309-315. doi:Doi 10.1016/S0022-3913(08)60212-7. 